\title{
UM ESTUDO SOBRE AS MEDIDAS PROVISÓRIAS NO BRASIL'
}

\author{
Carmem Arias \\ Mestranda em Ciências Sociais \\ na Universidade Estadual de Londrina
}

\section{Resumo}

Neste artigo pretendemos analisar o significado político assumido pelas medidas provisórias no Brasil. Os amplos poderes legislativos do presidente demonstram a fragilidade da democracia brasileira, e o grande número de medidas provisórias constitui-se uma evidência da invasão, por parte do Executivo, das atribuições do poder Legislativo.

Palavras-chave: democracia brasileira; medidas provisórias; Executivo e Legislativo.

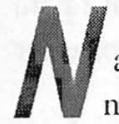

a idéia de democracia que surgiu no Brasil no período pós-regime militar está implícita uma íntima relação com os conceitos da democracia liberal, a qual resulta da fusão que se deu no século XIX entre as idéias de democracia e de liberalismo, e que, em linhas gerais, defende como valores universais a liberdade individual, a igualdade legal e a representação política dos cidadãos. Vale dizer que a teoria política liberal constitui-se um modelo que se reflete tanto na ideologia dominante no mundo contemporâneo como também na forma de representatividade política instituída na maioria dos Estados modernos, incluíndo o Brasil.

Como é notório, são várias as dificuldades encontradas pelos Estados contemporâneos para fazer com que estas duas exigências -

\footnotetext{
OO texto é uma adaptação da monografia $O$ autoritarismo na transição democrática brasilcira: um estudo sobre as medidas provisórias, apresentada como trabalho de conclusão do curso de Ciências Sociais - habilitação Bacharelado, da UEL, em dezembro de 2000 , sob orientação da professora Maria José de Rezende.
} 
limitar e distribuir o poder - sejam cumpridas. Num país que apenas recentemente conseguiu sair de um regime autoritário, como é o caso do Brasil, tais dificuldades são ainda maiores. É nesse contexto que tentaremos analisar a questão das medidas provisórias, a qual, em nossa opinião, reflete a dificuldade do Estado brasileiro de limitar e distribuir poder. A especificidade da nossa arena institucional, a que se caracteriza por uma tênue divisão entre os poderes Legislativo e Executivo e por uma relação tipicamente desigual entre estes dois poderes, contribui para que o Executivo continue mantendo a sua supremacia sobre o Legislativo no Brasil.

Assim, para que possamos extrair algumas das especificidades da política brasileira contemporânea, pretendemos trabalhar com alguns dados empíricos, principalmente no que se refere às medidas provisórias editadas ou reeditadas pelos diferentes governos instituídos desde a Constituição de 1988.

O estudo do conceito mais usual de democracia, o qual se fundamenta numa idéia de institucionalização do regime representativo e, por extensão, do espaço eleitoral, constitui-se um importante instrumento para a compreensão da organização da moderna política nacional e para a análise da natureza do Estado que se firmou no Brasil na fase posterior à "transição democrática" brasileira.

Visto que as medidas provisórias constituem-se un dos principais instrumentos institucionais garantidos pela Constituição ao chefe do Executivo, gostaríamos de deixar claro, desde já, que, para compreender as reformas institucionais que permearam a fase que se convencionou chamar de "transição democrática", teremos, necessariamente, de seguir pelo viés institucional de análise.

\section{Aspectos gerais quanto ao processo de transição no Brasil}

Maria José de Rezende parte do pressuposto de que num determinado momento foi necessário "inventar" a transição como forma de solucionar as diversas dificuldades políticas oriundas do modelo político-econômico posto em prática no pós-1964. 
A autora também deixa claro que a relação política estabelecida no interior do bloco de poder que sustentou a ditadura era muito mais complexa do que aparentava; o atendimento dos interesses econômicos não extinguia automaticamente a possibilidade de desenvolvimento de impasses políticos. (REZENDE, 1996,p.8)

No transcorrer do trabalho, a autora procura demonstrar a especificidade da natureza política desse pacto de domínio que, mesmo não sendo hegemônico, era absolutamente eficiente no que diz respeito às garantias dos interesses dos componentes do bloco de poder.

As propostas de Constituinte, Parlamentarismo, negociação, consenso, etc., esclareciam, de acordo com Rezende, as dificuldades políticas no interior do bloco de poder que advinham de um determinado tipo de relação com setores dominados, sobre os quais recaíam, mesmo no período da transição, os pesados ônus da repressão. A luta pela fabricação do consenso estava cunhada na ideologia de transição. No último governo militar, momento de crise econômica e política acirrada, os setores dominantes batiam-se para estabelecer alguma forma de consenso para validar o processo político que se desencadeava. A insistência em se definir um candidato ungido pelo apoio popular, por exemplo, tinha por objetivo recuperar a idéia de representação política e de que todos eram responsáveis pela solução dos problemas econômicos e políticos brasileiros. (REZENDE, 1996, p.12-13)

\section{A transformação do regime militar para o regime civil: as reformas institucionais}

De acordo com Bolívar Lamounier (1996, p.7), uma interpretação consistente da transição do regime militar ao civil é condição sine qua non para uma adequada avaliação das subseqüentes tentativas de reforma institucional e das dificuldades políticas que o país viveu desde meados da década de 1980.

Segundo ele, há uma distância histórica enorme entre a instauração, gradual ou abrupta, de um regime democrático e sua posterior consolidação: "Em países recém-saídos de experiências ditatoriais, a ins- 
tauração é um processo conceitualmente simples (o que não quer dizer politicamente fácil)'. (LAMOUNIER, 1996, p.7)

O problema, segundo ele, é que as mudanças institucionais (re)instauram, mas não asseguram a continuidade da democracia - $\mathrm{e}$ muito menos a qualidade de seu funcionamento. Aliás, como mostra a experiência brasileira de 1985 a 1993, as dificuldades podem ser gigantescas. (LAMOUNIER, 1996, p.8)

Lamounier (1996, p.16-17) discorda da idéia de que tivemos "um arranjo pelo alto, oligarquicamente concertado". De acordo com a sua interpretação, o processo da redemocratização brasileira - iniciado em 1974 e só concluído formalmente em março de 1985, com a posse de um presidente civil -, foi algo complexo e multiforme.

O conjunto da história política brasileira, e especialmente a experiência de 29 anos sob regimes autoritários (o Estado Novo e o regime militar pós-1964), demonstra, de acordo com Lamounier ( 1996. p.23), a hipertrofia do Executivo, uma vez que este esteve tradicionalmente munido de decretos-leis e ainda hoje é detentor de amplíssima iniciativa legislativa, na qual se inclui a prerrogativa de editar medidas provisórias, um instrumento de duvidoso teor democrático.

Amaury de Souza e Bolívar Lamounier, especulando sobre a tessitura constitucional e sobre a emergente forma de governo moldada por ela, em contraposição à realidade de uma sociedade secularmente caracterizada pela desigualclade e pela despolitização, mostram-se otimistas: "a nova Constituição do Brasil pode ser vista /.../ como um esforço coletivo para passar a limpo o país, desafiando atitudes profundamente arraigadas de hostilidade ou de ceticismo com relação ao regime democrático". (SOUZA; LAMOUNIER, 1990, p. 101)

No entanto, eles consideram matéria de preocupação determinar até onde o texto constitucional é congruente com a cultura política do país. E, nesse sentido, fazem a seguinte pergunta:

"Será a população, ou mesmo importantes segmentos da elite, tão tolerante, democrática e pluralista quanto a Constituição pressupõe? $\mathrm{Ou}$, tomando o assunto por outro lado, estará o cidadão suficientemente politizado para beneficiar-se, e ao mesmo tempo oferecer apoio, a esse novo sistema democrático e participativo estabelecido pela Constituição?'(SOUZA; LAMOUNIER, 1990, p.102) 


\section{As medidas provisórias revelando a fraqueza da democracia no Brasil}

O autoritarismo ainda presente na esfera política brasileira se reflete na prática política propriamente dita, o que fica evidenciado pelo uso excessivo de medidas provisórias por parte do poder Executivo. A Constituição Federal brasileira, promulgada em 5 de outubro de 1988, no Título IV - "Da Organização dos Poderes", Capítulo I - "Do Poder Legislativo", Seção VIII - "Do Processo Legislativo", Subseção III "Das Leis", no artigo 62, considera que a prática das medidas provisórias deve ser disciplinada nos seguintes termos:

"Em caso de relevância e urgência, o Presidente da República poderá adotar medidas provisórias, com força de lei, devendo submetê-las de imediato ao Congresso Nacional, que, estando em recesso, será convocado extraordinariamente para se reunir no prazo de cinco dias.

Parágrafo único. As medidas provisórias perderão eficácia, desde a edição, se não forem convertidas em lei no prazo de trinta dias, a partir de sua publicação, devendo o Congresso Nacional disciplinar as relações jurídicas delas decorrentes." (BRASIL, 1988)

Como podemos perceber, o texto é bastante genérico e vago, deixando margem para interpretações diversas quanto ao significado de palavras tão amplas e relativas tais como "relevância" e "urgência", por exemplo. Também fica explícito que há uma lacuna no parágrafo único: As medidas provisórias perderão eficácia /.../ se não forem convertidas em lei no prazo de trinta dias..., pois, como é notório, algumas medidas provisórias têm sido reeditadas " $n$ " vezes,' sem que o Congresso chegue sequer a se manifestar a respeito ${ }^{2}$.

Diante dos amplos poderes legislativos do presidente, os quais se evidenciam pelo uso/abuso das medidas provisórias, tudo leva a crer

I De acordo com um artigo de Gilse Guedes e Roberta Sampaio, publicado no jornal O Estado de S. Paulo, a medida provisória que estabelece a participação dos trabalhadores nos lucros das empresas já tinha sido reeditada 70 vezes (isto em 29/05/2000, quando o artigo foi publicado), e ainda não havia sido aprovada. (GUEDES: SAMPAIO, 2000) 
que há elementos que indicam uma continuidade da atual democracia com o regime militar. Nesse sentido, podemos afirmar que a prática das medidas provisórias pouco se diferencia dos decretos-leis ${ }^{3}$ do período militar. Entretanto, uma ressalva deve ser feita: não foram poucas as mudanças institucionais pelas quais o Estado brasileiro passou, principalmente nas duas últimas décadas.

\section{0 sistema de comissões no legislativo brasileiro}

Carlos Pereira e Bernardo Mueller pretendem contribuir para a criação de uma teoria que seja capaz de explicar as especificidades do caso brasileiro. Tal teoria, segundo eles, deverá ter como um de seus pressupostos centrais o fato de o Executivo brasileiro deter significativo poder de influenciar o processo legislativo, assegurando assim resultados consistentes com suas preferências. (PEREIRA; MUELLER, 2000, p.46)

Os referidos autores apresentam, logo na primeira seção do artigo, os poderes legislativos do Executivo brasileiro, ressaltando a sua extrema supremacia. Observam que o Executivo brasileiro tem diversos meios e instrumentos para contornar e controlar as comissões do Congresso, forçá-las a cooperar ou punir seus desvios e, levando-se em conta que as comissões estão prestando algum papel no processo legislativo e cumprindo uma tarefa que é do interesse do Executivo, concluem que as comissões são úteis ao Executivo e, consequientemente, não podem ser contrárias aos interesses do mesmo.

Nesse sentido, eles descrevem o poder de legislar do Executivo brasileiro e enfocam a sua habilidade em impor, mediante dispositivos institucionais, as suas preferências à legislação que esteja sendo decidida no Congresso. Assim, de acordo com os autores, dois aspectos do

$2 \mathrm{O}$ artigo foi entregue antes da regulamentação das Medidas Provisórias pelo Congresso Nacional (N. da C.E.)

3 O decreto-lei, como o próprio nome diz, é um decreto com força de lei. baixado pelo poder Executivo quando este acumula funções do poder Legislativo. Como é notório, o uso deste instrumento institucional foi uma prática frequiente durante o regime militar brasileiro. 
processo de tomada de decisão no Congresso brasileiro são fundamentais para o entendimento de como o Executivo controla o Legislativo: "o poder de legislar garantido ao presidente pela Constituição; e /.../ a centralização do poder decisório nas mãos dos líderes dos partidos no Congresso". (PEREIRA; MUELLER, 2000, p.46)

De acordo com Mainwaring e Shugart (apud PEREIRA; MUELLER, 2000, p.46-47), existem três categorias amplas de poderes constitucionais do presidente:

1) poderes legislativos pró-ativos, ou seja, aqueles que permitem ao presidente legislar e estabelecer um novo status quo o mais comum é a medida provisória;

2) poderes legislativos reativos, ou seja, aqueles que permitem ao presidente bloquear a legislação e, como consequiência, defender o status quo contra a maioria legislativa que queira mudá-lo - sobretudo vetos totais ou parciais; e

3) a capacidade do presidente para moldar ou até mesmo definir a agenda do Congresso, dado seu poder exclusivo de iniciar certos tipos de legislação.

A capacidade do presidente para legislar através de medidas provisórias é o principal poder pró-ativo do Executivo brasileiro. Este dispositivo institucional o autoriza a promulgar prontamente uma nova legislação, sem a necessidade de aprová-la no Congresso, pois, para que uma medida provisória permaneça em vigor não é necessário que a maioria do Congresso a aprove, mas apenas que a maioria não a rejeite. As medidas provisórias conferem ao presidente não só o poder de legislar, como também grande influência sobre a agenda do Congresso, assim, se o Congresso não bloquear uma medida provisória no prazo de trinta dias, ela vai automaticamente para o topo da agenda do Congresso, deslocando questões que vinham sendo discutidas prioritariamente. (PEREIRA; MUELLER, 2000, p.47)

De acordo com a Constituição, a medida provisória só deve ser usada em situações específicas, mas o que tem sido verificado na prática é que o Executivo brasileiro tem feito uso indiscriminado deste dispositivo. Por essa razão, não só o número total de medidas provisórias tem 
crescido muito a cada uma das últimas legislaturas, mas também muitas medidas vêm sendo reeditadas, um grande número de vezes, já que o Congresso raramente as desafia. Os dados apresentados na tabela que segue são bastante ilustrativos a esse respeito: desde que este instituto foi criado no Brasil, o número de medidas provisórias editadas e reeditadas vem crescendo vertiginosamente.

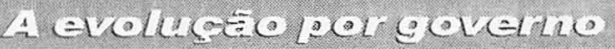

\section{Total de MPs novas e reeditadas}

\begin{tabular}{l|r|r|r|r} 
Govemo & Total & MPsnovas & $\begin{array}{l}\text { Médiamensal } \\
\text { de MPs novas }\end{array}$ & Reediçöes \\
José Sarney & 147 & 125 & 7,1 & 22 \\
Fernando Collor & 160 & 87 & 2,8 & 73 \\
Itamar Franco & 505 & 141 & 5,2 & 364 \\
FHC (1 ${ }^{\circ}$ mandato) & 2.609 & 160 & 3,3 & 2.449 \\
FHC $^{* *}\left(2^{\circ}\right.$ mandato) & 1.003 & 42 & 3,8 & 961 \\
Dois mandatos de FHC & 3.612 & 202 & 3,4 & 3.410 \\
Todos os governos* & 4.424 & 555 & 4,1 & 3.869
\end{tabular}

* Desde a Constituição de 1988, a qual instituiu as MPs.

** Até o dia 02/12/1999.

Fonte: Presidência da República (apud MADUEÑO: ULHÓA,1999).

No que tange ao poder reativo, vale enfatizar que o presidente pode rejeitar parcialmente propostas enviadas pelo Congresso bem como vetar propostas inteiras. O mais usual, no entanto, tem sido o veto total. Cabe notar que, embora a Constituição de 1988 tenha tornado relativamente fácil para o Legislativo reverter um veto presidencial, dado que isso requer somente maioria absoluta, durante toda a última legislatura (1995-98) o Congresso brasileiro não fez uso deste dispositivo institucional nem uma única vez. (PEREIRA; MUELLER, 2000, p.47)

Os dados analisados por eles confirmam que a área de atuação do Congresso, ao longo da legislatura 1995-98, foi restringida pela agenda 
do presidente: foram 648 propostas iniciadas pelo Executivo, aproximadamente $75 \%$ delas foram sobre temas ligados diretamente à economia, quase $17 \%$ propostas administrativas, e apenas $8 \%$ estavam relacionadas a temas políticos ou sociais. Por outro lado, das 141 propostas iniciadas pelos parlamentares, $56 \%$ eram das áreas política e social, cerca de $30 \%$ eram administrativas e $14 \%$ eram sobre a área econômica. Portanto, estes percentuais são bem ilustrativos quanto à divisão de tarefas no Congresso e, também, quanto aos mandatários de cada assunto.

Entretanto, há um outro fator determinante: o tempo médio para que uma proposta seja sancionada pelo Congresso, que, no caso das propostas iniciadas pelo Executivo foi de 183 dias; e no caso das propostas do Legislativo e do Judiciário, este prazo estendeu-se para 1194 e 550 dias, respectivamente. A taxa de aprovação de legislação com origem no Executivo está altamente associada com o pedido de urgência, um outro importante instrumento que o Executivo pode utilizar para interferir na tramitação de uma proposta no Congresso. Quando um pedido de urgência é feito, a comissão tem apenas duas sessões para examinar a proposta e votá-la antes de encaminhá-la para o plenário, o que, na prática, é um prazo muito curto e as comissões raramente conseguem examinar e se posicionar em relação a uma proposta que tenha recebido pedido de urgência.

Pedidos de urgência foram feitos sobretudo para propostas ligadas a temas econômicos e administrativos, que, como já ressaltamos anteriormente, têm sido os campos de maior interesse por parte do Executivo brasileiro. Quanto ao Legislativo, por sua vez, pode-se dizer, de acordo com Pereira e Mueller (2000, p.48), que quando ele pediu urgência para uma proposta, isso foi feito de acordo com os interesses do Executivo.

Pelo exposto até aqui, fica evidenciado que o Executivo brasileiro tem se servido de um poderoso conjunto de instrumentos para controlar a agenda do Congresso, bloqueando - através da combinação de dispositivos institucionais tais como medidas provisórias, vetos e pedidos de urgência - toda e qualquer legislação que não lhe seja conveniente, e promovendo aquelas que considera prioritárias.

Todavia, vale lembrar que as normas e instrumentos constitucionais não são os únicos fatores que colocam o Executivo numa posição privilegiada em relação ao Congresso; a centralização do 
processo de tomada de decisão dentro do Congresso também serve a este fim. As regras internas da Câmara garantem aos líderes dos partidos um papel central na condução do processo legislativo e na definição do sistema de comissões. Assim, o Executivo, através dos líderes do partido ou coalizão governista, manipula as nomeações de certas comissões, colocando nelas um número estratégico de membros fiéis aos seus interesses e/ou substituindo membros que lhe são menos leais.

A maneira pela qual os projetos são distribuídos às comissões e o fato de que, na prática, as posições de presidente, vice-presidente, secretário e relator são determinadas pelos líderes dos partidos (embora, oficialmente, estas posições sejam escolhidas por voto secreto e maioria absoluta dos votos dos membros da comissão a cada biênio), também são indicadores desta centralização do processo de tomada de decisão no Congresso brasileiro e, além disso, de acordo com os autores, demonstram um outro aspecto negativo: o fato de que o poder das comissões do Congresso brasileiro tem uma base institucional muito fraca.

Os autores afirmam que o emprego, por parte do Executivo, de alguns tipos de favores, tais como crédito, execução de emendas individuais dos parlamentares, concessões de rádio e televisão, licitações etc., é um outro instrumento amplamente utilizado como meio de obter apoio e votos para seus projetos e para fazer prevalecer suas preferências no Congresso. Isso ocorre, segundo os referidos autores, porque o Executivo no Brasil controla uma grande variedade de recursos e também porque diversos cargos importantes não são eletivos, sendo a nomeação de seus titulares fortemente influenciada pelo Executivo. (PEREIRA; MUELLER, 2000, p.50)

Com base em dados empíricos referentes à legislatura 1995-1998, Pereira e Mueller (2000) constataram que a composição da maioria das comissões constituídas neste período apresentava um alto índice de lealdade à posição do Executivo, o que, segundo eles, sugere que este tenha usado seus poderes legislativos para levar a composição das comissões a lhe ser favorável. Surge, portanto, a seguinte questão: o que as comissões podem fazer pelo Executivo que justifique que este despenda esforços para controlar sua composição? E, alguns parágrafos depois, eles mesmos respondem a ela com o seguinte argumento: "há, de fato, algo que as comissões podem fazer pelo Executivo quando as suas preferências são próxi- 
mas. A comissão/.../ é capaz de impedir que legislação contrária aos interesses do Executivo chegue ao plenário". (PEREIRA; MUELLER, 2000, p.52)

Sintetizando o que foi retratado até aqui, nesta seção dedicada à análise do sistema de comissões no Legislativo brasileiro, podemos afirmar, juntamente com os autores, que o fato mais marcante do Congresso brasileiro são os extensos poderes legislativos do Executivo. Em outros termos, vale dizer que a fragilidade de nossas comissões parlamentares é uma consequiência direta da extrema preponderância do Executivo, já que, como foi demonstrado, no Brasil, o Executivo, em virtude de seus amplos poderes no processo legislativo, consegue fazer que seus interesses prevaleçam no Congresso.

\section{A relação entre o legislativo e o executivo como base esclarecedora das edições das medidas provisórias}

Renato Lessa apresenta uma resenha do livro Executivo e Legislativo na nova ordem constitucional (de Argelina Figueiredo e Fernando Limongi) e afurma que a obra encerra um poderoso exercício de demolição de superstições.

Dadas as condições institucionais vigentes no país, não é necessário que a disciplina partidária seja gerada fora do Congresso. De acordo com Lessa (2000), Argelina Figueiredo e Fernando Limongi chegaram à conclusão de que não ocorre um predomínio de estratégias individualistas na arena parlamentar, visto que o controle centralizado, exercido pelos líderes partidários e, sobretudo, pelo Executivo, sobre a agenda e os trabalhos parlamentares, reduz as chances de sucesso de iniciativas puramente individuais dos deputados. A eficácia do trabalho do parlamentar individual está, portanto, associada a padrões fortes de disciplina partidária no interior do Legislativo.

Argelina Figueiredo e Fernando Limongi (apud LESSA, 2000) realizaram um estudo sistemático sobre o comportamento partidário parlamentar no período 1989-1994, com base em votações nominais. Por intermédio da análise de 221 votações nominais, eles detectaram que em $89 \%$ destas votações os resultados eram previsíveis tomando por base a posição dos líderes de bancadas. 
Segundo Lessa (2000), os autores demonstram, com base na análise das votações nominais na Câmara (atualizada até 1999, e incluindo votações de emendas constitucionais), que, no caso brasileiro, o controle da agenda legislativa por parte do Executivo aproxima o nosso tipo de presidencialismo da forma parlamentarista:

"O Executivo organiza o apoio a sua agenda em moldes semelhantes aos encontrados em países parlamentaristas. A distribuição de ministérios, por exemplo, entre as legendas que dão apoio ao governo faz com que 9 em cada 10 votos de parlamentares desses partidos sejam fiéis. O Legislativo, assim, não se apresenta como óbice à ação do Executivo, como faria supor uma avaliação formal do arranjo institucional brasileiro."

Quanto ao entendimento do que poderíamos designar como a República de 1988, Lessa esclarece que, segundo os autores, a Constituição de 1988 não significou um retorno aos quadros da República de 1946; para eles, é possível falar até mesmo de uma "continuidade legal" entre o experimento de 1964 e a República de 1988, ao menos no que diz respeito às normas que regulam as relações entre o Executivo e o Legislativo no Brasil. Tal descendência sustenta a preponderância legislativa do Executivo, em forte contraste com a experiência da República de 1946, pois, sob a Constituição de 1988, o Executivo tornou-se o principal legislador no Brasil.

Prosseguindo em suas análises, Lessa (2000) comenta que os sinais desta preponderância estão presentes na dilatada capacidade do Executivo para controlar a agenda dos trabalhos legislativos - tanto em termos de timing como de conteúdo -, através de mecanismos diversos, tais como a extensão da exclusividade de iniciativas do Executivo, o poder de editar medidas provisórias e a faculdade de solicitar urgência para os seus projetos. O efeito necessário é a presença de un padrão altamente centralizado de organização do Congresso, que acaba sendo estruturado pelos partidos políticos.

Uma das singularidades da República de 1988 é o alargamento das funções legislativas do Executivo. Quanto a esse aspecto, de acordo com os comentários de Lessa, é impossível desconsiderar o papel das medidas provisórias, o "mais poderoso instrumento legislativo" de que dis- 
põe o presidente. O diagnóstico é claro: "O Executivo garante sua preponderância legislativa e inibe o desenvolvimento institucional do Legislativo, sobretudo porque pode recorrer à edição e posterior reedição de medidas provisórias." (FIGUEIREDO; LIMONGI apud LESSA, 2000) Mas, o fato de que as medidas provisórias são uma criação dos parlamentares, ${ }^{+}$conforme Lessa (2000), sugere um instigante paradoxo:

"Buscando alguma racionalidade na manutenção por parte dos parlamentares de um instituto que suprime suas prerrogativas, os autores sugerem que as MPs foram utilizadas sobretudo com vistas à formulação de políticas macroeconômicas e associadas a temas impopulares, o que caracterizaria a presença de um padrão de delegação, mais do que abdicação, na tolerância parlamentar diante da incessante abundância de medidas provisórias."

É interessante notar que há uma grande concentração de poder nas mãos do Executivo e que este, mais do que a prerrogativa de editar e reeditar medidas provisórias, possui confortável maioria legislativa. A respeito disso, Lessa (2000), resgatando as hipóteses apresentadas por Argelina Figueiredo e Fernando Limongi, tece os seguintes comentários:

"O instituto da medida provisória /.../ converte-se em uma quimera
nas mãos de um Executivo majoritário, sobretudo se não regulada.
Seria o caso de enfatizar /.../ a possibilidade de que o uso obsessi-
vo das medidas provisórias tenha a ver não apenas com a relação
Executivo-Legislativo, mas com a que se estabelece entre o presi-
dente e os parlamentares de sua base. Aqui, além da pressa, pare-
ce operar a preocupação em reduzir custos de negociação no inte-
rior da própria coalizão de apoio ao presidente."

No Brasil, apenas nos sete primeiros anos de vigência da Constituição de 1988, mais de 1.200 medidas provisórias foram editadas, o que, segundo Lamounier (1996, p.55) demonstra uma forte tendência ao "governo por decreto".

+ De acordo com Adylson Motta, então deputado (PDS-RS), durante a Constituinte, 379 deputados votaram a favor das medidas provisórias, e apenas 66 parlamentares se colocaram contra este instrumento. (MOTTA apud CÂMARA... 1991. p.5) 
De acordo com Lamounier (1996, p.55), convém ressaltar que esta exacerbação do arbítrio legislativo na América Latina se deve ao presidencialismo e, também, em grande parte, à necessidade que têm os governos de realizar reformas econômicas estruturais ao mesmo tempo que procuram controlar a inflação, ou se encontram em ambientes ainda contaminados pela memória de superinflações crônicas.

Os impactos decorrentes da interdependência inerente ao processo de globalização econômica são relevantes para o debate latinoamericano. Os programas de estabilização e de reforma do setor público vinculam-se diretamente à globalização da economia. No contexto pós-Guerra Fria vem ocorrendo um estreitamento do leque de alternativas ideológicas, ou de política econômica, em escala mundial. Este pano de fundo, caracterizado pela crescente descrença em economias centralmente planejadas ou que contam com alta participação empresarial do Estado, explica, segundo Lamounier (1996), o substancial aumento do apoio a políticas de estabilização, ajuste do setor público e abertura comercial.

Esse estreitamento ideológico tem transformado as propostas governamentais de reforma estrutural em verdadeiros "pacotes" a serem "engolidos" pela população em geral, e parece ter dois efeitos potencialmente maléficos para a democracia representativa: o reforço exagerado do Executivo; e a exacerbação da legislação por fiat ao Executivo, isto é, do faça-se conforme decreta o Executivo.

Quanto à exacerbação do "governo por decreto", Lamounier (1996, p.55) afirma que esta tendência também é uma constante na história política latino-americana que "ocorre apesar do propalado 'aprofundamento da democracia' e do aparente vigor da 'sociedade civil' /..."'.

De acordo com Lamounier (1996, p.55), a utilização de instrumentos extremamente unilaterais de iniciativa legislativa, concebidos para situações excepcionais (os antigos decretos-leis e as atuais medidas provisórias), vem sendo banalizada, transformada em rotina. Segundo ele, esta exacerbação do "governo por decreto" ocorre, dentre outras razões, devido à relativa inegociabilidade das propostas de reforma.

A regulamentação do uso de medidas provisórias é um assunto polêmico e que, de alguns anos para cá, tem feito parte do debate polí- 
tico no Brasil. Com base em um levantamento que realizamos em alguns jornais, na sequiência, tentaremos apresentar algumas das propostas que foram formuladas pelos parlamentares brasileiros nesse sentido.

\section{0 debate político acerca da regulamentação do uso das Medidas Provisórias}

O Congresso vem tentando, desde 1990, limitar o poder do presidente para editar medidas provisórias. No dia 06/03/1991, por exemplo, a Câmara dos Deputados aprovou uma lei complementar, de autoria do então deputado Nelson Jobim, ${ }^{5}$ regulamentando e restringindo o uso de medidas provisórias pelo presidente da República. Os líderes do bloco governista se posicionaram a favor do projeto, mas, claro, com um "apoio relativo", ou seja, pretendiam manter ilimitado o poder do presidente para editar medidas provisórias e concordariam com o projeto Jobim desde que o governo mantivesse o poder de reeditar quantas vezes quisesse as medidas provisórias que não fossem votadas pelos parlamentares no prazo de trinta dias, e, além disso, o governo não abriria mão de baixar medidas provisórias sobre matéria tributária. (CÂMARA...1991)

Entretanto, já na época, ficava evidente que a aprovação na Câmara significava apenas a "vitória" parcial desses parlamentares que defendiam a regulamentação das medidas provisórias. A verdadeira batalha entre o governo e a oposição viria na fase de votação das emendas destacadas para exame em separado.

Portanto, vale ressaltar que o projeto parou quando chegou ao Senado: a proposta foi considerada inconstitucional pelo senador José Bisol, Segundo este, o tema só poderia ser tratado por emenda constitucional. (BISOL apud TREVISAN, 1995, p.6)

Na revisão constitucional, por sua vez, o tema voltou a ser tratado por Jobim, que deu parecer favorável a um projeto de emenda que

5 Neste ponto, queremos chamar a atenção do leitor para um fato que nos parece um tanto quanto sugestivo: Nelson Jobim, autor de um projeto de lei que regulamentava e restringia o uso de medidas provisórias pelo presidente da República (quando deputado, en 1991), fora "promovido", em janeiro de 1995 , à posição de ministro da Justiça do governo Fernando Henrique Cardoso. 
impunha limite ao poder de legislar do Executivo. A proposta, no entanto, nem chegou a ser votada. (TREVISAN, 1995)

De acordo com Ulysses Guimarães (o qual fora o presidente da Assembléia Constituinte), a medida provisória é um elemento que só pode ser usado "excepcionalissimamente", ou, em suas próprias palavras: "Medida provisória é decreto-lei, e nós temos de acabar com essa maldição que há sobre o País, de que tudo é provisório, desde a economia, à política salarial." (GUIMARÃES apud CÂMARA... 1991, p.5)

No início de 1995, a questão da restrição ao uso de medidas provisórias pelo Executivo voltava à tona e dizia-se que este seria um dos principais temas a ser discutido pelos parlamentares que iriam tomar posse no dia $1^{\circ}$ de fevereiro: "Se as restrições propostas forem aprovadas, o presidente Fernando Henrique Cardoso não terá a seu dispor o que chamou de 'ditadura benigna' das medidas provisórias." (TREVISAN, 1995)

Há muitas medidas provisórias em vigor e que ainda não foram sequer analisadas pelos parlamentares, o que, segundo Esperidião Amin, é uma situação cômoda para o Congresso. Na sua opinião, o grande número de medidas provisórias se deve à inação do Legislativo e à voracidade do Executivo; uma coisa não existiria sem a outra. (AMIN apud TREVISAN, 1995)

De acordo com José Genoino, é na quebra dessa relação "promíscua" que se estabeleceu entre os dois poderes nessa área, que se encontra o caminho para o Congresso resgatar suas funções constitucionais. (GENOINO apud TREVISAN, 1995)

A título de ilustração, vale lembrar que no período compreendido entre 5 de outubro de 1988 (quando foi promulgada a Constituição, a qual criou a medida provisória) e $1^{\circ}$ de janeiro de 1995 , foram aprovadas 1.035 leis pelos 503 deputados federais e 81 senadores que compunham o Congresso Nacional e detinham o poder constitucional de legislar. No mesmo período, os presidentes José Sarney, Fernando Collor, Itamar Franco e FHC editaram 831 medidas provisórias (incluindo as reedições), as quais têm força de lei desde a data de sua publicação.

A diferença entre o número de leis e o de medidas provisórias demonstra o abismo que vem se estabelecendo entre a atividade legislativa do Congresso e a do Executivo no Brasil. O Plano Real, por exemplo, foi instituído em 29/06/1994, por meio da edição de uma medida 
provisória. Todavia, cabe destacar que esta não foi a primeira mas sim a quinta vez que uma mudança tão drástica na economia brasileira foi feita através de medidas provisórias. Em todas as situações, os parlamentares se depararam com fatos consumados (como a troca da moeda do país, por exemplo), diante dos quais não lhes restava outra alternativa senão aprovar as decisões do Executivo.

De acordo com Celso Bastos, temos no Brasil uma medida que é a mais forte de todas as que são usadas em países democráticos. Em sua opinião, o uso da medida provisória no Brasil é abusivo e chega a ser pior clo que o uso dos decretos-leis durante o regime militar, porquanto, para que o presidente faça uso do instrumento das medidas provisórias não há limitação constitucional de temas, enquanto que para os decretos-leis havia limitação de temas; eles só podiam tratar de finanças públicas, segurança nacional e criação de cargos públicos e vencimentos. (BASTOS apud TREVISAN, 1995)

Como a decisão é do presidente, há medidas provisórias sobre quase tudo - além da mudança de moeda, o Executivo tem tratado de questões tributárias, mensalidades escolares e diretrizes de ensino, venda de carros populares e regras orçamentárias -, para citar apenas alguns temas. O impacto delas na vida do cidadão brasileiro tem sido bem maior do que o das leis aprovadas por iniciativa do Congresso, já que as leis propostas pelos parlamentares raramente têm a abrangência das medidas provisórias. (TREVISAN, 1995)

O levantamento de dados que realizamos em alguns jornais de circulação nacional reforça esta idéia de que os temas abrangidos pelas medidas provisórias são realmente muitos. São alguns exemplos: o pacote para abrir o mercado, as medidas para a desburocratização, as medidas provisórias tratando dos salários e, sobretudo, do salário mínimo, tratando de locações de imóveis residenciais e comerciais em regiões urbanas, desregulamentando a área cambial, atingindo a política fiscal, o crédito rural, a saúde e o ensino, para citarmos algumas das áreas contempladas pelas medidas provisórias durante o governo Fernando Collor: O ex-presidente Itamar Franco, por sua vez, lançou mão de medidas provisórias para compor o Plano Real.

O conteúdo das medidas provisórias perde-se em meio às brigas e interesses de aliados. O critério de "relevância e urgência" exigido 
para sua edição nem sempre é considerado, o que tem originado casos curiosos e medidas provisórias sobre assuntos os mais fortuitos assuntos, da compra de um carro para seu vice (como aconteceu com o então presidente Fernando Collor) à proibição de importar coco (como ocorreu no primeiro mandato de Fernando Henrique Cardoso). (GUEDES; SAMPAIO, 2000, p.4)

Citando apenas os sete primeiros meses de governo, Fernando Henrique Cardoso emitiu quase o dobro do que Itamar Franco assinou em 27 meses; quatro vezes mais do que Sarney em 17 meses e meio; e seis vezes mais do que Collor em 30 meses e meio. Ou seja, com a média mensal de 34,4 medidas provisórias, Fernando Henrique Cardoso tem emitido mais de uma medida provisória por dia - e ainda mais se considerarmos apenas os dias úteis. (FREITAS, 1995, p.5)

Cabe lembrar que Fernando Henrique Cardoso foi crítico do que também ele considerava abuso de medidas provisórias por parte de Sarney e, quando candidato, assegurou numerosas vezes que as restringiria ao papel que a Constituição lhe prescreve.

Para Celso Antônio Bandeira de Mello, enquanto existirem medidas provisórias, o governo brasileiro lançará mão delas abusivamente, sem nenhuma consideração pelo direito e sem temer contestação significativa por parte dos demais poderes, dos meios de comunicação ou da sociedade em geral. De acordo com ele, isso ocorre porque, no Brasil, o chefe do Executivo desfruta, psicologicamente, de status de soberano, de imperador. É inconscientemente considerado como tal porque, entre nós, vive-se com uma entranhada mentalidade de "súdito", não de cidadão. Em suma, para ele, no Brasil o que há é sentimento espontâneo, genuíno de vassalagem. (BANDEIRA DE MELLO, 1996, p.3)

De acordo com Ney Suassuna, não só o volume de medidas provisórias, mas também a evolução da sua utilização nos governos após a Constituição de 1988 acusam um crescimento vertiginoso. Para ele, o fato de o governo ter "herdado" medidas provisórias dos seus antecessores não justifica a reedição das mesmas. Logo, não prospera o argumento dado pelo governo de que existem muitas MPs herdadas dos antecessores: a cada trinta dias o governo toma, livremente, a decisão de enviar esta ou aquela medida provisória, devendo assumir a responsabilidade da iniciativa da sua reedição. (SUASSUNA, 1996, p.3) 
A rigor, inexiste a reedição. O Congresso Nacional recepciona cada MP, original ou reeditada, como se nova fora, uma vez que o processo legislativo é iniciado em seus primórdios: é publicada no Diário Oficial da União, encaminhada por meio de mensagem ao Congresso Nacional, feita a leitura em plenário, indicados os membros, instalada a comissão e fixados os prazos de tramitação, exatamente nos mesmos moldes de medida que chega pela primeira vez ao Congresso.

Finalmente, deve-se ressaltar, de acordo com Suassuna (1996), a co-responsabilidade do Legislativo perante a situação atual. De um lado, o Executivo abusa do conceito de urgência e relevância para abarrotar o Congresso de medidas provisórias, usurpando a sua competência de legislar; de outro, o Congresso não se empenha efetivamente em votar aquelas em tramitação nem em disciplinar o seu uso.

Neste jogo de conveniência, perde o país, que passa a ter um ordenamento jurídico provisório. Aliás, conforme assinala Suassuna (1996), é tão constrangedor o volume de MPs em tramitação no Congresso que o governo, recentemente, adotou um artifício para esquivarse do rótulo de usurpador: passou a fazer acompanhar o número da MP de um dígito indicativo da quantidade de reedições, buscando, dessa forma, atribuir parte da responsabilidade pelo escândalo quantitativo do instrumento aos seus antecessores.

Quando senador, Fernando Henrique Cardoso atacou o excesso de medidas provisórias do governo Collor. Em 1990, na coluna semanal que publicava no jornal Folha de S.Paulo, o então senador criticou a "enxurrada de medidas provisórias", dizendo que ela representava o "abuso da paciência e da inteligência do país".

No artigo supracitado, Fernando Henrique Cardoso também criticou o ex-presidente José Sarney, afirmando que as medidas provisórias no governo Sarney passaram a ser editadas como se fossem os antigos decretos-leis. Entretanto, há um aspecto importante a ser considerado: embora Sarney tenha editado um total de 138 medidas provisórias, ele conseguiu que elas fossem aprovadas no Congresso rapidamente, tanto é que só reeditou 22 delas. (FRANÇA, 1998, p.4)

$\mathrm{O}$ artigo de Fernando Henrique Cardoso foi escrito antes de ele se tornar ministro do governo Itamar Franco - o presidente que mais editou e reeditou MPs, se pensarmos o curto tempo de seu mandato. ${ }^{6} \mathrm{O}$ 
Plano Real, lançado em julho de 1994, quando FHC era ministro da Fazenda de Itamar Franco, foi colocado em prática por meio de medida provisória, ato criticado por ele em seu artigo, e tramitou (sendo reeditada) durante 14 meses no Congresso Nacional até ser aprovada e se tornar a lei 9.069/95. (FRANÇA, 1998)

O chefe da assessoria parlamentar do governo, Eduardo Graeff, não vê abusos na edição e reedição de MPs por FHC, e disse que, se o presiclente Fernando Henrique Cardoso edita as medidas provisórias, "é porque tem o que propor e precisa de leis para mudar”. (GRAEFF apud FRANÇA, 1998)

Segundo Graeff, o fato de que, até então, havia 1.839 reedições de MPs no governo FHC, deve-se, sobretudo, a uma falha do Congresso: "Os deputados e senadores estão votando outras coisas. Basta olhar a pauta de votações. Não se consegue marcar sessões conjuntas para votar as MPs - elas são muito poucas." (GRAEFF apud FRANÇA, 1998)

Para Graeff, o fato de essas votações não estarem ocorrendo não significa falta de apoio do Congresso ao presidente: Ele tem sempre recebido apoio ao que propõe. Essas MPs que estão sendo reeditadas /.../ não preocupam, porque não há questionamentos. Se houvesse, estariam sendo discutidas com prioridade.

Em junho de 1990, em seu artigo, Fernando Henrique Cardoso afirmava:

"O Executivo abusa da paciência e da inteligência do país quando insiste em editar medidas provisórias sob o pretexto de que, sem sua vigência imediata, o Plano Collor vai por água abaixo e, com ele, o combate à inflação.

Com esse ou com pretextos semelhantes, o governo afoga o Congresso numa enxurrada de 'medidas provisórias'. O resultado é lamentável: Câmara e Senado nada mais fazem do que apreciálas aos borbotões." (CARDOSO apud FRANÇA, 1998)

E, prosseguindo em seus comentários sobre as medidas provisórias, o então senador dizia que o Congresso poderia aprová-las, modificá-las ou rejeitá-las na íntegra. Todavia, perguntava: "O que ocorre depois de eventual rejeição da medida provisória pelo Congresso?" E,

- Vale lembrar que em pouco mais de dois anos de mandato, o presidente Itamar Franco editou 141 MPs novas e, se incluídas as reedições, un total de 505 MPs. 
logo na sequiência, ele mesmo respondia: "A Constituição é muda sobre a matéria. Quando a elaboramos, o pressuposto era o de que tais medidas seriam remédio extremo, realmente urgente e relevante." (CARDOSO apud FRANÇA, 1998)

Segundo ele, a responsabilidade pela enxurrada de medidas provisórias tem co-responsabilidade: Executivo e Legislativo. E, diante desta relação viciosa entre os poderes, alguns parágrafos depois, ele foi taxativo em seus argumentos:

"É certo, porém, que, seja qual for o mecanismo, ou o Congresso põe ponto final no reiterado desrespeito a si próprio e à Constituição, ou então é melhor reconhecer que no país só existe um 'poder de verdade', o do presidente. E daí por diante esqueçamo-nos também de falar en 'democracia'.”' (CARDOSO apud FRANÇA, 1998)

O presidente do Senado, Antonio Carlos Magalhães (PFL-BA), criticou o presidente Fernando Henrique Cardoso por estar contra o projeto que restringe $\mathrm{o}$ uso de medidas provisórias, aprovado no dia $1^{\circ}$ de dezembro de 1999: "O governo não quer trabalhar. A base do governo não quer trabalhar. Viver autoritariamente, para quem pregava a democracia, é intolerável." (MAGALHÃES apud MADUEÑO; ULHÔA, 1999, p.6)

O porta-voz da Presidência, Georges Lamazière, disse, na época, que a preocupação de Fernando Henrique Cardoso com esse projeto que visava restringir o uso de MPs "não era com a diminuição dos poderes do presidente". Segundo ele, o presidente temia que o Congresso viesse a ter dificuldade para trabalhar e temia o bloqueio de atividades legislativas. (LAMAZIËRE apud MADUEÑO; ULHÔA, 1999)

O líder do governo no Senado, José Roberto Arruda, admite que, por causa da facilidade de reedição, o Planalto não costuma articular-se para aprovar MPs: "O governo envolve-se na negociação quando o caso é polêmico, como foi a fixação do salário mínimo." (ARRUDA apud GUEDES; SAMPAIO, 2000)

Fogaça responsabiliza os parlamentares pelas reedições de MPs: "O Congresso não se pronuncia sobre isso para não entrar em bola dividida com o Executivo e a sociedade, já que grande parte das MPs trata de assuntos impopulares." (FOGAÇA apud GUEDES \& SAMPAIO, 2000) 
O jurista Celso Antônio Bandeira de Mello diz que esta prática tornou-se tão freqüiente que, hoje, o Congresso só pode cumprir uma agenda regular de apreciação de MPs se houver moderação do Executivo. Ele constatou que, do início do primeiro mandato de Fernando Henrique Cardoso até agosto de 2000, foram editadas 3.239 MPs, uma média de quase 2,8 por dia útil de governo, apenas 89 delas foram aprovadas. (BANDEIRA DE MELLO apud GUEDES; SAMPAIO, 2000)

O texto atual da proposta de emenda constitucional que restringe o uso de medidas provisórias não garante maior autonomia ao Legislativo. Para especialistas, as restrições previstas no projeto do deputado Roberto Brant não tiram a força das MPs, já que a emenda permite que elas vigorem por até quatro meses. (GUEDES; SAMPAIO, 2000)

Vigência de até quatro meses, de acordo com Fabiano Santos (cientista político do Iuperj), é tempo suficiente para criar um fato na vida social, difícil de ser revertido pelo Congresso, pois este fica refém dos efeitos jurídicos que começam a ser produzidos imediatamente e a reversão disso pode ser custosa. Segundo ele, isso ocorre principalmente na área econômica, que costuma ser a campeã na regulamentação de temas por MPs. (SANTOS apud GUEDES; SAMPAIO, 2000)

As críticas do deputado Miro Teixeira, autor de emenda que próbe a reedição e a prorrogação de MPs, vêm no mesmo senticlo: "Matérias financeiras e cambiais produzem resultados no mesmo dia e não se pode rejeitar seus efeitos quando se tem um fato consumado." (TELXEIRA apud GUEDES; SAMPAIO, 2000)

Finalizando, vale lembrar que de acordo com a Constituição de 1988, as medidas provisórias devem ser submetidas de imediato ao Congresso. Entretanto, na prática, dificilmente são votadas pelos parlamentares: como entram em vigor de imediato, com força de lei, acabaram se transformando em um instrumento do Executivo para legislar sem a ameaça de interferência do Congresso.

\section{Considerações finais}

A organização política dos Estados democráticos contemporâneos tem passado por grandes transformações internas devido ao impacto 
provocado pela globalização econômica. Para as democracias recém-saídas de regimes autoritários, como é o caso do Brasil, as dificuldades têm sido ainda maiores. A democracia brasileira tem-se mostrado frágil diante da preponderância de um Executivo ávido em legislar.

Procuramos apresentar alguns aspectos referentes à democracia brasileira, tentando identificar algumas de suas especificidades. Conforme foi exposto, são várias as dificuldades encontradas pelo Estado brasileiro para limitar e distribuir o poder. O uso de medidas provisórias, emitidas para os mais diversos fins, mas destinadas principalmente para a área econômica e tributária, evidencia a necessidade que os últimos governos vêm tendo para alinhar o país a uma economia transnacional.

Diante dessa perspectiva, tentamos demonstrar que a questão das medidas provisórias é bastante complexa e se insere no contexto da divisão tênue entre os diferentes poderes do Estado. Constatamos a existência de um Legislativo aparentemente omisso, um Judiciário que pouco atua e um Executivo que tem invadido os outros dois poderes, legislando por intermédio das constantes edições e reedições de medidas provisórias, o que caracteriza uma prática política eminentemente autoritária e denota a fragilidade da democracia brasileira também no período posterior à promulgação da nova Constituição.

A preponderância do Executivo brasileiro e os poderes legislativos do presidente são mais um indício de que a nossa herança cultural autoritária continua arraigada tanto na sociedade civil como na vida política brasileira. A divisão aparentemente tênue entre os poderes, na realidade, oculta uma relação de forças bastante desigual entre os poderes Executivo, Legislativo e Judiciário no Brasil.

As medidas provisórias têm interferido no cotidiano do cidadão brasileiro, nos campos econômico e social, entretanto, embora este seja um tema polêmico e considerado abusivo por muitos, ainda pouco foi feito ou mesmo discutido no sentido de promover alguma mudança no texto constitucional que criou o instituto da medida provisória no Brasil.

Cabe observar, finalmente, que não tivemos a pretensão de fazer uma leitura única ou esgotar o assunto e sim contribuir para o debate, mesmo porque a questão das medidas provisórias é bastante complexa e abrangente e pode ser enfocada sob várias perspectivas de análise. 


\section{Referências Bibliográficas}

BANDEIRA DE MELLO, Celso Antônio. Sobrevivência piorada do decreto-lei. Folha de São Paulo, São Paulo, 11 maio 1996. Caderno 1. p.3.

BRASIL. Constituição, 1988. Constituição da República Federativa do Brasil. Brasília: Senado Federal, 1988.

CÂMARA aprova projeto sobre as MPs. O Estado de São Paulo, São Paulo. 7 mar. 1991. Caderno A, p.5.

FRANÇA, William. FHC ultrapassa Collor em $\mathrm{n}^{\circ}$ de medidas provisórias. Folha de São Paulo, São Paulo, 14 mar. 1998. Caderno 1, p. 4.

FREITAS, Janio de. Medida permanente. Folha de São Paulo, São Paulo. 27 jul. 1995. Caderno 1, p.5.

GUEDES, Gilse; SAMPAIO, Roberta. Oposição quer modificar emenda que limita MPs. O Estado de São Paulo, São Paulo, 29 maio 2000. Caderno A. p.4.

LAMOUNIER, Bolívar. A democracia brasileira no limiar do século 21. São Paulo: Centro de Estudos Konrad Adenauer-Stiftung, 1996.

LESSA, Renato. Superstições políticas. Folha de São Paulo, São Paulo. 11 mar. 2000. Caderno Especial, Jornal de Resenhas, p.10.

MADUEÑO, Denise; ULHÔA, Raquel. Para ACM, governo 'não quer trabalhar'. Folha de São Paulo, São Paulo, 3 dez. 1999. Caderno 1. p.6.

PEREIRA, Carlos; MUELLER, Bernardo. Uma teoria da preponderância do poder Executivo: o sistema de comissões no Legislativo brasileiro. Revista Brasileira de Ciências Sociais, São Paulo, v.15, n.43, p.45-67. jun. 2000.

REZENDE, Maria José de. A transição como forma de dominação política: o Brasil na era da abertura - 1980-1984. Londrina: Ed. UEL, 1996.

SOUZA, Amaury de; LAMOUNIER, Bolívar. A feitura da nova Constituição: um reexame da cultura política brasileira. In: LAMOUNIER. Bolívar (Org.). De Geisel a Collor: o balanço da transição. São Paulo: Sumaré, 1990. p.81-104.

SUASSUNA, Ney. Crescimento vertiginoso. Folha de São Paulo. São Paulo. 21 dez. 1996. Caderno 1, p.3.

TREVISAN, Cláudia. Presidência faz mais leis que o Congresso. Folha de São Paulo, São Paulo, 22 jan. 1995. Caderno 1, p.6. 


\section{Abstract}

In the present article, we want to analyse the political meaning of "temporary measures" in Brazil. The ample legislative powers of the president show the fragility of Brazilian democracy and the large number of "temporary measures" represents an evidence of executive preponderance in Brazil.

Key-urords: brazilian democracy; "temporary measures"; Executive and Legislative. 